\title{
Two Types of Non-Noun-Incorporation
}

\author{
Ileana Paul \\ University of Western Ontario
}

\section{Introduction}

The goal of this paper is to investigate cases of apparent noun-incorporation in Malagasy, a western Austronesian language spoken in Madagascar. ${ }^{1}$ Looking at examples such as those in (1), one may ask whether or not Malagasy has nounincorporation.

(1) a. Rovi-body ny harona.

torn-bottom DET basket

'The basket has a torn bottom.' [K\&R: (4b')]

b. Mandatsa-bato izy.

AT.drop-stone 3(NOM)

'She votes.'

[K\&R: (21c)]

In (1), there is a bare noun (vody 'bottom' and vato 'stone' - the [b] is the result of a phonological rule) adjacent to the matrix predicate. Examination of these data reveal two key facts. First, despite the surface similarities between (1a) and (1b), the two bare nouns in (1) have very different structure: the first is an NP, the second is a DP with a null $\mathrm{D}^{\circ}$. Second, neither example illustrates nounincorporation, as traditionally understood, whether lexical compounding or head adjunction. Instead, I will show that (1a) is an example of pseudo nounincorporation, as proposed for Niuean by Massam (2001). The example in (1b), on the other hand, involves simple juxtaposition.

The organization of this paper is as follows: I begin with a general discussion of the distribution of nominals in Malagasy - with and without determiners. In section 3 I turn to the two constructions illustrated in (1) and compare and contrast them. Section 4 details the analyses of the two constructions and I conclude the paper in section 5 .

\section{Background facts}

\section{$2.1 \mathrm{DPs}$}

Malagasy is a VOS language with fairly rigid order. Regular nominals (proper names, nouns with determiners/demonstratives) can appear in any argument position, as shown in (2) for ny vehivavy 'the woman', which is underlined in each example.

(2) a. SUBJECT

Mihiry ny vehivavy.

AT.sing DET woman

'The woman is singing.' 
b. DIRECT OBJECT

Manaja ny vehivavy Rasoa.

AT.respect DET woman Rasoa

'Rasoa respects the woman.'

c. INDIRECT OBJECT

Nanome boky ny vehivavy Rasoa.

PS.AT.give book DET woman Rasoa

'Rasoa gave a book to the woman.'

d. OBJECT OF A PREPOSITION

Tezitra amin'ny vehivavy Rasoa.

angry with'DET woman Rasoa

'Rasoa is angry with the woman.'

I will henceforth refer to such nominals as DPs, given the presence of a determiner/demonstrative. ${ }^{2}$ Object DPs can scramble rightwards past adverbs.

(3) a. Mamitaka ny ankizy matetika Rabe. AT.trick DET child often Rabe

'Rabe often tricks the children.'

b. Mamitaka matetika ny ankizy Rabe. AT.trick often DET child Rabe

'Rabe often tricks the children.'

Thus DPs in Malagasy have a "normal" argument distribution.

\subsection{Other nominals}

There are two types of bare nominal, corresponding to (1a) and (1b). I will illustrate each in turn.

\subsubsection{Bare possessees}

Malagasy has what appears to be possessor raising, discussed in detail by Keenan and Ralalaoherivony (2000). As shown by $K \& R$, there are two main types: possessor raising to subject and possessor raising to object. The first is illustrated in (4) and (5): the possessor of the subject becomes the subject and the possessee is demoted to within VP. ${ }^{3}$ Note that the possessee loses its determiner. The (b) examples are the raising versions of the (a) examples. Thus in (4a), Rabe is the genitive-marked possessor of ny zanaka 'the child', while in (4b) Rabe is the nominative subject.

(4) a. Marary ny zana-dRabe. sick DET child.GEN.Rabe

'Rabe's child is sick.'

b. Marary zanaka Rabe.

sick child Rabe

'Rabe has a sick child.'

[K\&R: (3)] 
(5) a. Rava ny tranony. destroyed DET house.3(GEN)

'Her house was destroyed.'

b. Rava trano izy. destroyed house 3(NOM)

'She was house-wrecked.'

$\left[\mathrm{K} \& \mathrm{R}:\left(4 \mathrm{~d}, \mathrm{~d}^{\prime}\right)\right]$

K\&R provide ample evidence that the clause-final DP in these examples is the subject.

Instances of possessor raising to object are not as widespread, but K\&R give several examples. As illustrated in (6) and (7), the possessor of the object becomes the object, while the possessee is demoted, losing its determiner. In (6a), ny gadra 'the prisoner' is the genitive possessor of ny fatorana 'the bonds', while in (6b) ny gadra is an accusative object (accusative case is overtly marked on pronouns).
(6)a. Manala
ny fatoran'ny gadra
Rabe.
AT.remove
DET bond.GEN.DET prisoner Rabe
'Rabe removes the prisoner's bonds.'
b. Manala
fatorana
ny gadra
Rabe.
AT.remove
bond
DET prisoner Rabe
'Rabe bond-removes the prisoner.'

[K\&R: $\left.\left(60 \mathrm{~b}, \mathrm{~b}^{\prime}\right)\right]$

(7)
Manety
ny volon-janany
Rabe
AT.cut
DET hair.GEN.child.3(GEN)
Rabe
'Rabe cut his child's hair.'

b. Manety volo an-janany

AT.cut hair ACC-child.3(GEN) Rabe

'Rabe hair-cut his child.'

[K\&R: $\left.\left(60 a, a^{\prime}\right)\right]$

In the remainder of this paper, I refer to the bare possessee (e.g. zanaka 'child' in (4b) or fatorana 'bond' in (6b)) as BP.

\subsubsection{Bare objects}

The other type of bare nominal appears as the direct object (usually a patient or theme) of a verb. If the verb and the noun have the correct phonological form, the two optionally "bond" to form one phonological word. Simplifying somewhat, bonding occurs when the predicate ends in $-n a,-k a$ or - tra. This syllable drops and the first consonant of the noun, if it is a fricative, becomes a stop. The resulting word (written with a hyphen), has one main stress as shown in (8), where I use the acute accent to indicate main stress. (See Rajemisa-Raolison 1971 for discussion and further examples.)

(8) a. Mánana vóla izy.

$\rightarrow \quad$ Mànam-bóla izy.

AT.have money 3(NOM)

'She has money.' 

b. Mangálatra fáry izy. $\rightarrow$ Mangàla-páry izy. AT.steal sugar-cane $3(\mathrm{NOM})$ 'She steals sugar cane.'
c. Mandátsaka váto izy. $\quad \rightarrow \quad$ Mandàtsa-báto izy. AT.drop stone 3(NOM)
'She votes.'
[K\&R: (21)]

It thus appears that noun has incorporated into the verb. I call these bare direct objects BO.

\section{The status of bare nouns}

In comparison with DPs, discussed in section 2.1 , all bare nouns have a very restricted distribution. Moreover, all bare nouns look the same at first glance. But despite their surface similarities, the two types of bare noun have very different syntactic and semantic properties.

\subsection{The similarities}

As seen in example (1), repeated in (9), both BP and BO have similar phonological effects. That is, given a verb with the right phonological shape, the bare noun bonds with the verb.

(9) a. Rovitra vody ny harona. torn bottom DET basket 'The basket has a torn bottom.'

b. Mandatsaka vato izy. AT.drop stone 3(NOM) 'She votes.' $\rightarrow \quad$ Rovi-body ny harona.

[K\&R: (4b')]

$\rightarrow \quad$ Mandatsa-bato izy.

[K\&R: (21c)]

Moreover, both types of bare noun must be string-adjacent the verb and cannot be separated from the verb by an adverb. ${ }^{4}$ The examples in (10) and (11) illustrate this order for $\mathrm{BP}$, those in (12) for BO. Note that in this way, bare direct objects differ from DP direct objects (see example (3)).

(10) possessor raising to subject
a. Maty vady tampoka Rabe. dead spouse suddenly Rabe 'Rabe was suddenly widowed.'
b.* Maty tampoka vady Rabe. dead suddenly spouse Rabe

[K\&R: $(19 b, c)]$

(11) possessor raising to object
a. Nanendaka akanjo an-keriny an-dRabe Rasoa. AT.tear-off clothes ACC-force ACC-Rabe Rasoa 'Rasoa tore Rabe's clothes off by force.' 
b. Nanendaka an-keriny akanjo an-dRabe Rasoa. AT.tear-off ACC-force clothes ACC-Rabe Rasoa

$[\mathrm{K} \& \mathrm{R}:(63 b, c)]$

(12) во
a. Mamitaka ankizy matetika Rabe. AT.trick child often Rabe
'Rabe often tricks children.'
$\begin{array}{clll}\text { b. } \begin{array}{cl}\text { Mamitaka } \\ \text { AT.trick }\end{array} & \begin{array}{l}\text { matetika } \\ \text { often }\end{array} & \begin{array}{l}\text { ankizy } \\ \text { child }\end{array} & \text { Rabe. } \\ \text { Rabe }\end{array}$

Thus bare nouns show a certain dependency on the verb, with both phonological and syntactic effects.

This dependency, however, may be interrupted in non-active sentences, where the genitive agent must appear next to the verb. (13) is an example of a BP: the noun volo 'hair' appears next to the verb in (15a), but appears after the genitive agent in (15b).
(13)a. Manety volo an-janany Rabe. AT.cut hair ACC-child.3(GEN) Rabe 'Rabe cut his child's hair.'
b. Hetezan-dRabe volo ny zanany. TT.cut.GEN.Rabe hair DET child.3(GEN) 'His child has his hair cut by Rabe.

[K\&R: (60a'),(48a')]

Example (14) shows the same effect with во: the bare noun akanjo 'clothes' appears after the genitive agent in (14b).

(14)a. Nividy akanjo ho an'ny ankizy Rasoa. AT.buy clothes for ACC'DET child Rasoa 'Rasoa bought clothes for the children.'

b. Nividianan-dRasoa akanjo ny ankizy. CT.buy.GEN.Rasoa clothes DET child 'Rasoa bought clothes for the children.'

[K\&R: $(23 a, b)]$

Note that these examples show that the bare noun and the predicate do not form a lexical compound. I return to this point in section 4.

\subsection{Differences}

Despite the surface similarities, there are important differences between BP and BO. First, as pointed out by $\mathrm{K} \& \mathrm{R}$, BPS are non-referential. It is impossible to refer to them by a pronoun in later discourse, as shown in (15a). On the other hand, BOs do introduce a discourse referent that can be referred to, as shown in (15b). ${ }^{5}$
(15)a.?*Maty vady
Rabe. Efa
antitrantitra
(izy).
dead spouse
Rabe already
oldish
(3.NOM)
'Rabe was widowed. She was already oldish.' [K\&R: (16b)] 

$\begin{array}{llll}\text { b. Manam-bady } & \text { Rakoto } & \text { ary tiany } & \text { izy. } \\ \text { AT.have-spouse } & \text { Rakoto } & \text { and love.3(GEN) } & \text { 3(NOM) }\end{array}$
'Rakoto has a wife and loves her.'

Second, the nominalizations of verbs with BP and BO are different. For possessor raising, the genitive agent appears obligatorily outside of the $\mathrm{BP}$, as illustrated by the contrast between (16a) and (16b).

(16)a. ny fahakingan-tsain-dRasoa

DET NM.CT.quick-spirit.GEN.Rasoa

'Rasoa's intelligence'
b.* ny fahakingan-dRasoa saina
DET NM.CT.quick.GEN.Rasoa spirit
'Rasoa's intelligence'

[K\&R: $(26 \mathrm{~d}, \mathrm{e})]$

In the nominalization of a verb with a $\mathrm{BO}$, on the other hand, the genitive agent comes between the verb and the Bo (similar to the non-active sentence in (14b)), as seen in (17).
(17)a. ny fangalaran-dRasoa fary
DET NM.CT.steal.GEN.Rasoa sugar
'the theft of sugar cane by Rasoa'
b.* ny fangalara-parin-dRasoa
DET NM.CT.steal-sugar.GEN.Rasoa
'the theft of sugar cane by Rasoa'

As a final difference, a BP may be modified, but such modification is limited, as discussed by $\mathrm{K} \& \mathrm{R}$. A BO, however, can easily be modified, taking relative clause modifier in (18b).

(18)a. Maty zanaka hendry Rabe. dead child wise Rabe

'Rabe suffers the death of his well-behaved child.' [K\&R: (32a)]
b. Manam-bola nangalarinao aho.
AT.have-money PST.CT.steal.2SG(GEN) 1SG(NOM)
'I have the money that you stole.'

In sum, BPs and BOs appear similar on the surface. A closer look at syntactic and semantic properties, however, reveals important differences between the two.

\section{The syntax of bare nouns}

In order to account for the differences between BPS and BOS, I suggest that they have different structures. In particular, BPs are NPs, while BOs are DPs. 


\subsection{Bare possessees}

Following recent research on applicatives and related constructions (Pylkkänen 2002, Lee-Schoenfeld 2003), I suggest that possessor raising in Malagasy is a type of applicative. There is an applicative head projected in the structure, as the complement to the main verb. ${ }^{6}$ The possessor is a DP projected in the specifier position and the possessee is the NP complement of the applicative head.

Turning first to possessor raising to subject, the verb is intransitive and has no case features. The possessor DP requires case and raises to the first available case position, the subject position. The possessee, being an NP does not require case and remains in-situ. This is precisely what Massam (2001) calls "pseudo nounincorporation". The tree in (19b) provides the structure of (19a).
(19)a. Marary zanaka Rabe.
sick child Rabe

'Rabe has a sick child.'

b.

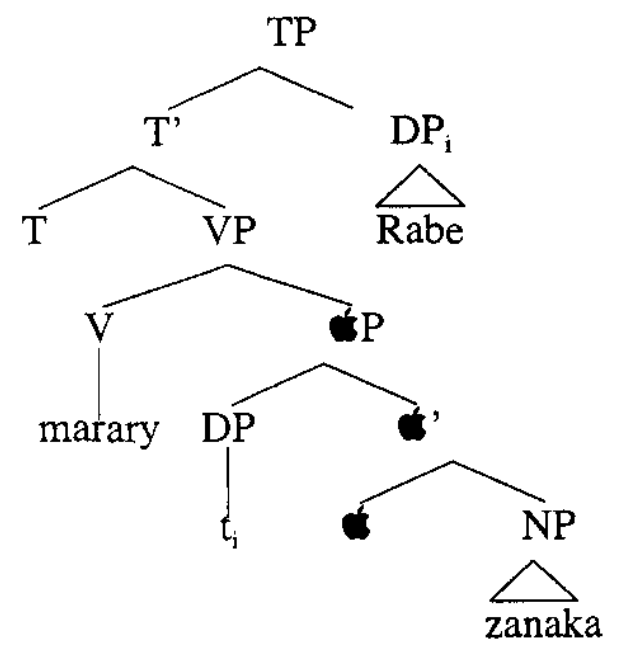

For possessor raising to object, the base structure is the same. But the host verb is transitive and therefore has the ability to assign accusative case. The possessor can therefore raise to a case position within the verbal projection, which I assume to be right-adjoined to $\mathrm{vP}$ (we saw earlier that objects scramble rightwards in Malagasy). As with the previous example, the possessee does not move. The example in (20) illustrates this possibility.
(20)a. Manety volo an-janany
Rabe.
AT.cut hair ACC-child.3(GEN) Rabe
'Rabe cuts his child's hair.' 
b.

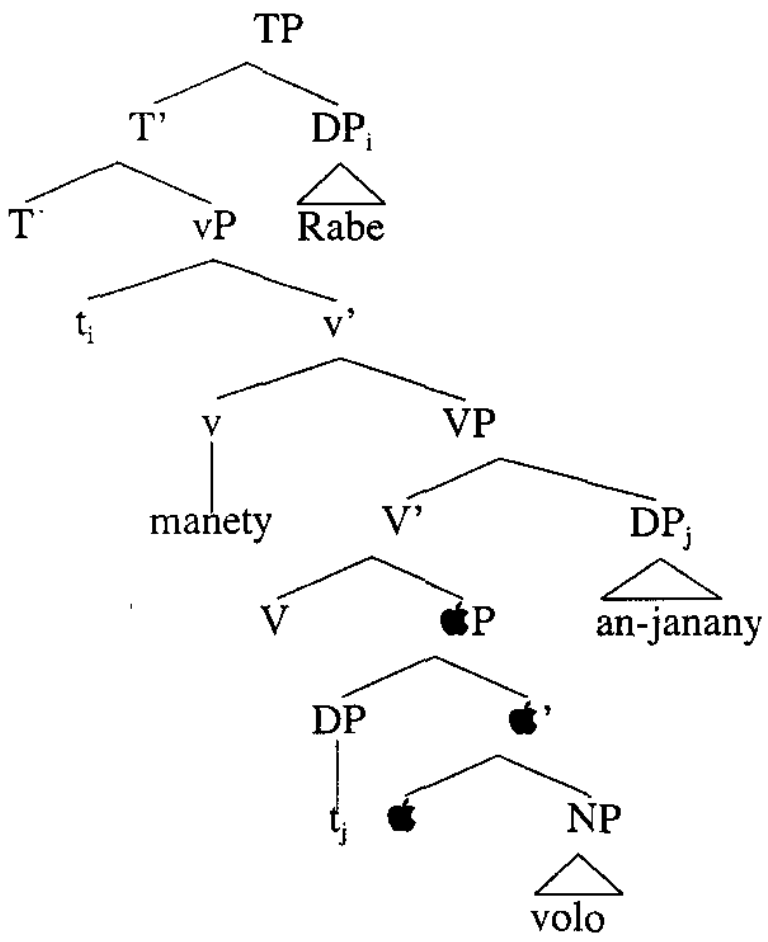

The proposed analysis accounts for the properties of the bare nouns (BPS) in possessor raising. Recall that BPs are interpreted as non-referential. Example (21a) shows that the possessee may not appear with a determiner. Example (21b) (repeating (15a)) shows that possessee does not introduce a discourse referent. Finally, (21c) illustrates the narrow scope of a BP: it obligatorily scopes under adverbs such as indroa 'twice'.

(21)a.* Maty ny vady Rabe. dead DET spouse Rabe

b.?*Maty vady Rabe. Efa antitrantitra (izy). dead spouse Rabe already oldish (3.NOM)

'Rabe was widowed. She was already oldish.' [K\&R: (16b)]

c. Maty vady indroa Rabe. dead spouse twice Rabe 'Rabe was twice widowed.' \# 'Rabe's wife died twice.'

[K\&R: (15a)]

These data suggest that a BP is non-referential and I therefore conclude that it is an NP, lacking the DP layer that corresponds to referentiality.

As mentioned above, possessor raising, under this approach, is a kind of pseudo noun-incorporation (Massam 2001). Massam argues that what has been called noun incorporation in Niuean does not involve true incorporation. She shows that the incorporated element can be bigger than just a noun, but smaller than a full DP. Massam therefore concludes that the seemingly incorporated element is an NP, lacking case features and inert for syntactic movement. Her conclusions for Niuean fit nicely with the Malagasy possessor raising facts. The 
BP is in fact syntactically inert and cannot be extracted, as shown by the ungrammaticality of (22).

$(22) *$ Volo no hetezan-dRabe an-zanany. hair FOC TT.cut.GEN.Rabe ACC-child.3(GEN)

'It is his child's hair that Rabe is cutting.' (and not his nails)

On the other hand, a BP is not syntactically incorporated into the verb, nor does it form a lexical compound with the verb. Thus elements such as genitive agents can intervene between the verb and the BP (as seen in (13b), repeated in (23a)) and a BP can be coordinated (23b), ruling out a head movement analysis (movement would violate the Coordinate Structure Constraint).

(23)a. Hetezan-dRabe volo ny zanany. TT.cut.GEN.Rabe hair DET child.3(GEN) 'His child has his hair cut by Rabe.

b. Maty vady aman-janaka Rakoto.

[K\&R: (48a')] dead spouse with-child Rakoto

'Rabe suffers the loss of his wife and child.'

Thus the pseudo noun-incorporation analysis of possessor raising best accounts for the range of data.

\subsection{Bare objects}

Turning now to Bо, I follow a suggestion by Zribi-Hertz and Mbolatianavalona (1997) that Malagasy has a null determiner, the covert counterpart of ny 'the'. In other words, BOs are in fact full DP arguments. The null determiner accounts for the fact that BOS can be interpreted as either definite or indefinite and for the possibility of relative clause modifiers, if relative clauses attach to the DP layer (24a). Moreover, as we have already seen, BOs introduce referents into the discourse (24b). Finally, because BOs are regular DP arguments, they are syntactically active and can be extracted (24c).

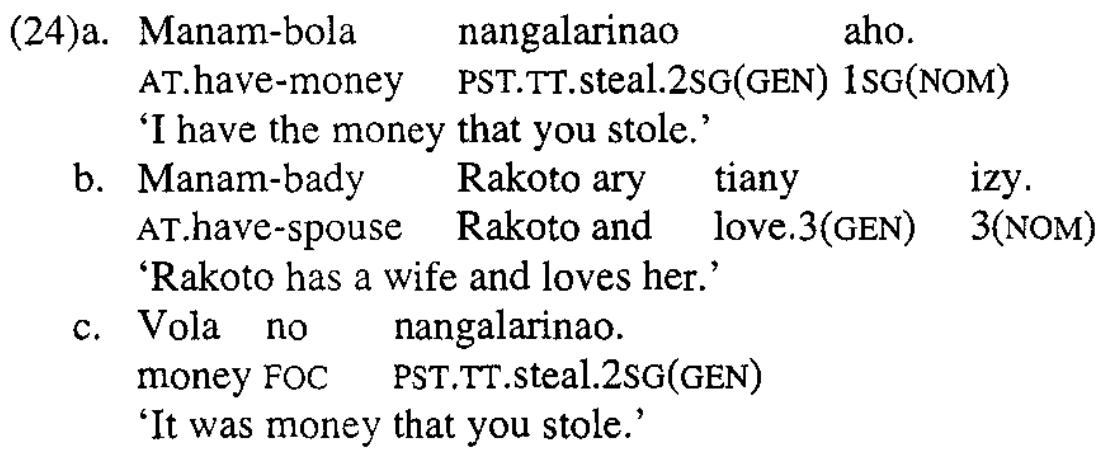

To account for the ordering of bos directly after the predicate, I suggest that the null determiner must be licensed under adjacency to the predicate (Longobardi 1994). An adverb interrupts this adjacency (see (12)), but a genitive agent does 
not (see (14)). This difference may arise due to the syntactic bonding that occurs between a genitive agent and a non-active predicate (perhaps via Chung's (1998) subject lowering), but I set this question aside for future research.

In sum, positing a null determiner in the above examples accounts for their syntactic and semantic properties, as well as distinguishing BPS from BOs.

\subsection{What about phonology?}

Although the proposed distinction between BPS and BOs accounts for their differences, it leaves open the question of their similarities. In particular, why do both trigger the bonding process?

(25)a. Rovitra vody ny harona. torn bottom DET basket 'The basket has a torn bottom.'

b. Manana vola izy. AT.have money 3(NOM)

'She has money.' $\rightarrow \quad$ Rovi-body ny harona.

[K\&R: (4b')]

$\rightarrow \quad$ Manam-bola izy.

[K\&R: (21a)]

I suggest that this bonding is a purely phonological process that is insensitive to syntactic structure. As mentioned earlier, bonding is optional and is determined by the phonological shape of the words rather than by syntax. Other examples of bonding show that this process is active in many different contexts, not just predicate+noun (see Rajemisa-Raolison 1971 for more examples). The example in (26a) illustrates bonding between a noun and a conjunction and (26b) shows bonding between an adjective and the noun it modifies.

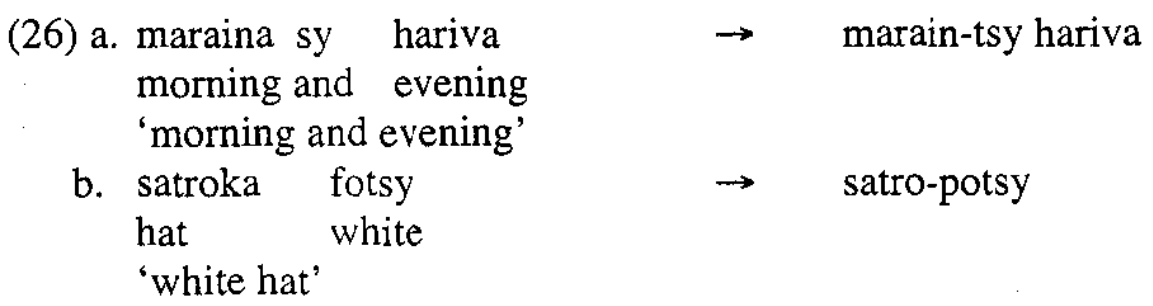

Bonding therefore tells us nothing about the structure of BPs or BOs.

\section{Conclusion}

This paper has examined what appeared to be bare noun arguments in Malagasy. I have argued that in the case of possessor raising, the bare possessee is an NP. This is therefore an instance of pseudo noun incorporation (Massam 2001). Bare direct objects, however, have been shown to be full DPs, with a null $\mathrm{D}^{\circ}$. Thus other than the presence of a null rather than overt determiner, these bare nouns are in fact regular DP arguments. 


\section{Endnotes}

ACKNOWLEDGMENTS: I would first like to thank the Malagasy speakers who helped me with the data: Saholy Hanitriniaina and Jeannot Fils Ranaivoson. I would also like to thank the participants of AFLA XI for their helpful comments and suggestions. Any errors, however, remain my own responsibility. Funding for this research was made possible in part by a Canada Research Chair (Tier II) grant.

1. Most of the data in this paper are from Keenan and Ralalaoherivony (2000), henceforth $K \& R$. Other data are from my own interviews with native speakers of Malagasy. I have slightly modified some of K\&R's glosses and translations.

2. Proper names also have a determiner in Malagasy, usually $R a$ or $i$.

3. I will discuss the exact position of the possessee in section 4.1.

4. Some exceptions to this adjacency will be discussed below.

5 . The referentiality of the Bo needs to be examined in a wider range of examples.

6 . I use the term 'verb' very broadly here to include non-verbal predicates, such as adjectives.

\section{References}

Chung, Sandra. 1998. The design of agreement: Evidence from Chamorro. Chicago: The University of Chicago Press.

Keenan, Edward and Baholisoa Ralalaoherivony. 2000. Raising from NP in Malagasy. Lingvisticae Investigationes 23: 1-44.

Lee-Schoenfeld, Vera. 2003. German possessor datives: Raised and affected. Ms., UCSC.

Longobardi, Giuseppe. 1994. Reference and proper names: A theory of Nmovement in syntax and logical form. Linguistic Inquiry 25: 609-695.

Massam, Diane. 2001. Pseudo noun-incorporation. Natural Language and Linguistic Theory 19: 153-197.

Pylkkänen, Liina. 2002. Introducing arguments. PhD thesis, MIT.

Rajemisa-Raolison, Régis. 1971. Grammaire malgache. Fianarantsoa: Ambozontany.

Zribi-Hertz, Anne and Liliane Mbolatianavalona. 1997. De la structure à la reference : les pronoms du malgache. Les pronoms : morphologie, syntaxe et typologie, ed. by Anne Zribi-Hertz. Saint-Denis: Presses Universitaires de Vincennes.

Ileana Paul

Department of French

University of Western Ontario

London, ON N6A3K7

Canada

ileana@uwo.ca 